\title{
Clinical significance of sonographic soft markers: A review
}

Mi Sun Kim, Sukho Kang, and Hee Young Cho*

Department of Obstetrics and Gynecology, CHA Bundang Medical Center, CHA University School of Medicine, Seongnam, Korea

Sonographic findings with little or no pathological significance, known as soft markers, are often found in aneuploidy fetuses. After normal screening for the aneuploidy in first trimester, there are no uniform recommendations regarding when to disregard or put on clinical significance in isolated soft markers. Associations between some soft markers and adverse pregnancy outcomes including intrauterine fetal death, preterm birth, fetal growth restriction, and congenital infection have been reported in euploidy fetuses. The present article aims to review recent literatures about the clinical significance of soft markers after normal first trimester combined screening or noninvasive prenatal testing, and propose a simple clinical summary for management of specific soft markers in pregnancies.

Key words: Aneuploidy, Ultrasonography.

\section{Introduction}

In past several decades, ultrasound screening during the second trimester to identify fetal anomalies has developed and improved remarkably. Some sonographic findings are structural signs with little or no pathological significance, commonly known as soft markers [1-3]. Generally studied soft markers include fetal ventriculomegaly (VM), choroid plexus cyst (CPC), absent or hypoplastic nasal bone, a thickened nuchal fold (NF), intracardiac echogenic focus (IEF), echogenic bowel, short long bones, pyelectasis, and single umbilical artery (SUA). Soft markers are common and they are not usually associated with any handicaps, unless there is an associated chromosomal abnormality [4].

The ultrasound soft markers are found in the 5 major chromosomal aneuploidies: trisomies 21, 18, and 13; Turner syn- drome; and triploidy $[5,6]$. Use of the soft markers may increase the positive predictive value in patients with first trimester combined screening (FTS) (combination of maternal age, biochemical screening tests of free $\beta$-hcg and PAPP-A, and nuchal translucency) [7]. Routine karyotyping of all pregnancies with these markers would have major implications, both in terms of miscarriage and in economic costs. However, the introduction of noninvasive prenatal testing (NIPT) with cell-free fetal DNA from maternal plasma may enabled to deal with soft markers as indicators of fetal chromosomal abnormalities $[1,4,7]$. NIPT is used for screening trisomies 21,18 , and 13 and potentially some sex chromosome aneuploidies and some microdeletion [8]. Its sensitivity for trisomy 21 approaches $99 \%$ but these tests do not provide information on other chromosomal aberrations [9]. NIPT and invasive prenatal testing are acceptably offered in high risk population (advanced maternal age, abnormal FTS results, his-

Received: 22 December 2017, Revised: 16 March 2018, Accepted: 22 March 2018, Published: 30 June 2018

${ }^{*}$ Corresponding author: Hee Young Cho, M.D. (D) http://orcid.org/0000-0001-7064-5056

Department of Obstetrics and Gynecology, CHA Bundang Medical Center, CHA University School of Medicine, 59 Yatap-ro, Bundang-gu, Seongnam 13496, Korea.

Tel: +82-31-780-5985, Fax: +82-31-780-5069, E-mail: hycho.md@gmail.com

Conflict of interest: The authors declare that they do not have any conflicts of interest.

(c) This is an open-access article distributed under the terms of the Creative Commons Attribution Non-Commercial License (http://creativecommons.org/licenses/by-nc/4.0/) which permits unrestricted non-commercial use, distribution, and reproduction in any medium, provided the original work is properly cited.

(c) Copyright 2018 by the Korean Society of Medical Genetics and Genomics www.e-kjgm.org 
tory of fetal aneuploidy, known balanced translocation, or other chromosomal rearrangements in one of the parents) with soft marker and those with any combination of two soft markers $[4,6]$. However, fetus with structural abnormality by ultrasound should be offered diagnostic testing with chromosomal microarray because there is a substantial risk that a chromosomal abnormality other than trisomy 21,18 , and 13 is present in the fetus which will not be detected by NIPT [9].

As soft markers were introduced as markers for aneuploidy in high risk population, there have been efforts for clarification of their significance after normal FTS or NIPT $[1,4]$. In this low risk population, soft markers were found in $5.9 \%$ of fetuses at second trimester ultrasound; markers were isolated in 5.1\%, multiple in 0.7\%, and combined with anomalies in 0.1\% [1]. Most cases (95\%) had a single marker, 4\% had two markers, and $1 \%$ had three or more markers when soft markers were first identified [10]. Diagnostic testing should not be recommended to patients with an isolated soft marker in the setting of a negative NIPT result [9]. Also, looking for soft markers of trisomy 21, should not be performed in women with a normal NIPT result due to its high false-positive rate and poor positive predictive value [11]

Previous studies reported isolated echogenic bowel was associated with an increased risk of congenital anomalies, and preterm birth. Isolated pyelectasis was associated with an increased risk of congenital anomalies of the kidneys or urinary tract. Multiple soft markers were associated with an increased risk of congenital anomalies and preterm birth [3,6,12-15]. It is essential to provide information to the parents about the observed soft markers and its potential impact on prenatal and postnatal life. This paper will review recent literatures about the most common second trimester sonographic soft markers and propose a simple clinical guideline for management of specific soft markers in pregnancies (Table 1) [3,6,10,12-36] .

\section{Ventriculomegaly}

Fetal VM is defined as a dilatation of the lateral ventricle atrium to a width of $10 \mathrm{~mm}$ or more. A measurement of 10-12 $\mathrm{mm}$ is commonly referred to as mild VM, while measurement of $12-15$ and $>15 \mathrm{~mm}$ are defined as moderate and severe VM. Its prevalence varies between 0.3 and 1.5 per 1,000 births [16]. VM have been associated with normal variant, aneuploidy, genetic syndromes, primary brain abnormalities, congenital infection such as cytomegalovirus (CMV) and toxoplasma, cerebrovascular accidents and intracranial hemorrhage [16-18]. Isolated mild and moderate VM regresses or become stable in diameters contrast to severe VM. In the systematic review and meta-analysis of Scala et al. [16], the fetuses with isolated unilateral VM had $0 \%$ chromosomal abnormalities, $8 \%$ congenital infection, and in about $5 \%$ of fetuses, there is progression of VM during the course of the pregnancy. The prevalence of neurodevelopmental delay in cases of apparently isolated unilateral mild or moderate VM was 6\%, and in severe VM it was 7\%. High rates of cerebral palsy, seizures and impaired motor capabilities were observed in severe VM [16-18]. The prevalence of neurodevelopmental delay in bilateral mild and moderate VM varies between $8 \%$ and $12 \%$ [19]. Magnetic resonance imaging can be used for further elucidation of cases with ventricular enlargement [18]. The overall prognosis of VM strongly depends on both the extent of enlargement and/or the presence of other abnormal findings or structural malformations. Also, asymmetric pattern of VM is a potential risk factor for anomalies of neuropsychological development [18]. Screening for congenital infection should be part of prenatal workup, especially if VM with increased periventricular echogenicity, calcification, periventricular pseudocysts and intraventricular synechia [37]. Diagnosis of toxoplasma and CMV infection is based on positive specific immunoglobulin M results with confirmatory immunoglobulin $\mathrm{G}$ avidity test. In case of a positive result for toxoplasma infection in maternal serum, amniocentesis is performed to determine the presence of the pathogen in the amniotic fluid by amplification of DNA, using polymerase chain reaction [38]. Repeated ultrasound scans to follow VM size or extension of VM are recommended because it is correlated with the prognosis [16-19].

\section{Choroid plexus cyst}

CPC is a small sonographically discrete fluid-filled space $\geq 5$ $\mathrm{mm}$ within the choroid plexus and CPC is seen as black echofree areas. CPC is found in approximately 2 to $4 \%$ of fetuses at 16 to 24 weeks of gestation usually as an isolated finding in otherwise normal low-risk pregnancy $[1,20]$. CPC typically regresses by 23 weeks regardless of karyotype [13]. There is an association between CPCs and chromosomal defects, particularly trisomy 18. However, the majority of fetuses with trisomy 18 have multiple other defects. Risk of amniocentesis is not justified if CPC is an isolated finding and amniocentesis is only acceptable if other major anomalies are present $[6,21]$. Women with isolated CPC and negative FTS and NIPT, the finding of CPC may be described as not clinically significant or as a normal variant [9]. CPC is not considered a structural nor functional brain abnormality [4]. Iso- 
lated CPCs in fetuses with normal karyotypes do not affect child mental and motor development after birth [22].

\section{Absent or hypoplastic nasal bone}

Absent of hypoplastic nasal bone, defined by a nasal bone that is not visible in first trimester or with a length of less than $2.5 \mathrm{~mm}$ in the mid-sagittal section of the fetal profile in second trimester, however the nasal bone length appears to be shorter in Korean fetuses than Caucasian and Chinese fetuses and is necessary to refer to race standards [39], and is described as one of the many phenotypic features of Down syndrome [6]. Cicero et al. [23] reported that in 73\% of trisomy 21 fetuses, the nasal bone was not visible at the 11-14 week scan. First trimester screening for trisomy 21 based on maternal age and fetal nuchal translucency detects about 70\% of affected fetuses for a 3\% false positive rate and with additional assessment of nasal bone, the detection rate increases to about 80\% with the same false positive rate [40]. It has been estimated that between 0.5 to $2.8 \%$ of euploid fetuses will have images consistent with delayed ossification of the nasal bone in either first-or second trimester sonography [23]. The absence of a fetal nasal bone warrants a detailed evaluation of fetal anatomy. If there are no other anomalies and normal karyotype, it is reasonable to reassure

Table 1. Proposal of a simple clinical summary for management of specific soft markers in pregnancies

\begin{tabular}{|c|c|c|c|}
\hline Marker & Incidence (\%) & Conditions & Considerations and follow-up \\
\hline Ventriculomegaly [16-19] & $3.0-15$ & $\begin{array}{l}\text { Aneuploidy } \\
\text { Genetic syndrome } \\
\text { Primary brain abnormalities } \\
\text { Congenital infection (CMV and } \\
\text { toxoplasma) } \\
\text { Cerebrovascular accidents } \\
\text { Intracranial hemorrhage }\end{array}$ & $\begin{array}{l}\text { TORCH screening } \\
\text { Follow-up scans to look for progression } \\
\text { Consider brain magnetic resonance imaging if moderate to severe } \\
\text { ventriculomegaly for detection of additional brain abnormalities }\end{array}$ \\
\hline Choroid plexus cyst [20-22] & $2-4$ & Aneuploidy (esp. trisomy 18) & Detail evaluation for other markers of aneuploidy \\
\hline $\begin{array}{l}\text { Absent or hypoplastic nasal } \\
\text { bone }[23,24]\end{array}$ & $0.5-2.8$ & $\begin{array}{l}\text { Aneuploidy (esp. trisomy 21) } \\
\text { B-cell immunodeficiency } \\
\text { Cri-du chat syndrome } \\
\text { Partial trisomy } 20 \text { q }\end{array}$ & $\begin{array}{l}\text { Detailed evaluation of fetal anatomy } \\
\text { Consider microarray studies (if with additional sonographic } \\
\text { anomalies) }\end{array}$ \\
\hline Thickened nuchal fold $[10,25]$ & $0.4-0.6$ & $\begin{array}{l}\text { Down syndrome } \\
\text { Congenital heart disease }\end{array}$ & Evaluation of fetal heart, consider fetal echocardiography \\
\hline $\begin{array}{l}\text { Intracardiac echogenic focus } \\
\text { [26-28] }\end{array}$ & $3-4$ & Down syndrome & $\begin{array}{l}\text { Detail evaluation for other markers of aneuploidy } \\
\text { More attention if multiple and right ventricle involved }\end{array}$ \\
\hline $\begin{array}{l}\text { Echogenic bowel } \\
{[3,6,12,13,29]}\end{array}$ & $0.2-1.8$ & $\begin{array}{l}\text { Aneuploidy } \\
\text { Intrauterine growth restriction } \\
\text { Intrauterine fetal demise } \\
\text { Cystic fibrosis } \\
\text { Congenital infection (esp. CMV) } \\
\text { Gastrointestinal anomaly }\end{array}$ & $\begin{array}{l}\text { Evaluation for cystic fibrosis } \\
\text { TORCH screening } \\
\text { 32-week ultrasound to assess for bowel dilatation or obstruction }\end{array}$ \\
\hline $\begin{array}{l}\text { Shortened humerus and } \\
\text { femur length [30-32] }\end{array}$ & $0.4-3.9$ & $\begin{array}{l}\text { Aneuploidy } \\
\text { Structural abnormalities } \\
\text { Skeletal dysplasia } \\
\text { Preeclampsia } \\
\text { Preterm delivery } \\
\text { Oligohydramnios } \\
\text { Intrauterine fetal demise } \\
\text { Intrauterine growth restriction }\end{array}$ & $\begin{array}{l}\text { 32-week ultrasound to assess growth and to rule out certain } \\
\text { skeletal dysplasia } \\
\text { Frequent blood pressure measurement } \\
\text { Study umbilical and uterine artery Doppler flow } \\
\text { Surveillance in timing of delivery }\end{array}$ \\
\hline Pyelectasis [3,13-15] & $0.1-2.4$ & $\begin{array}{l}\text { UPJ obstruction } \\
\text { Vesicoureteral reflux } \\
\text { Posterior urethral valves } \\
\text { Ureteral obstruction } \\
\text { Other renal abnormalities }\end{array}$ & $\begin{array}{l}\text { 32-week ultrasound to assess kidneys } \\
\text { Follow-up scans to look for progression } \\
\text { Postnatal follow-up if }>7 \mathrm{~mm}\end{array}$ \\
\hline $\begin{array}{l}\text { Single umbilical artery } \\
\text { [33-36] }\end{array}$ & $0.5-5$ & $\begin{array}{l}\text { Controversial } \\
\text { Aneuploidy } \\
\text { SGA } \\
\text { Preterm birth } \\
\text { Increase cesarean section rate }\end{array}$ & $\begin{array}{l}\text { Undergo targeted anatomical survey (level II ultrasound) } \\
\text { Controversial-ultrasound to assess growth }\end{array}$ \\
\hline
\end{tabular}


that the likelihood of a good neonatal outcome is high. However, case reports have described an absent fetal nasal bone in Bcell immunodeficiency, cri du chat (5p-) syndrome, and partial trisomy 20q. Considering these cases, microarray studies could be performed in addition to a fetal karyotype when an absent fetal nasal bone occurs with additional sonographic anomalies [24].

\section{Thickened nuchal fold}

Thickened NF is defines as, thickening of the skin and the subcutaneous tissues on the posterior aspect of the fetal neck measuring $6 \mathrm{~mm}$ or greater before $20+6$ weeks' gestation. Its prevalence is 1 to 6 per 1,000 [3]. Bromley et al. [10] concluded in their retrospective study, that especially thickened NF in second trimester is the most important soft marker in the detection of Down syndrome among fetuses who have had normal first trimester sonographic screening for aneuploidy [6]. Therefore, karyotyping should be offered when thickened NF is observed [10]. Controversially, diagnostic testing in setting of a negative NIPT screen with isolated soft marker is not recommended in other guideline [9]. Large randomized controlled trials will be needed in management of thickened NF. Some recent data indicate a positive association between NF measurement and congenital heart defects, with reported adjusted odds ratio of 14.8 (95\% confidence interval [Cl], 5.4-40.1). One in every 23 pregnancies with a NF measurement $\geq 5 \mathrm{~mm}$ had a congenital heart disease (sensitivity $=3.3 \%$, specificity $=99.6 \%$ ). Therefore, a targeted ultrasound with particular attention to the fetal heart is reasonable when a thickened NF is identified after normal fetal karyotyping [25].

\section{Intracardiac echogenic focus}

IEF is defined as an echogenic small spot inside the heart having brightness equivalent to that of the bone. Regarding the location, $88 \%$ are found in the left ventricle and $5 \%$ in right ventricle. They are found in about 3 to $4 \%$ of normal fetuses and in about 25\% of those with trisomy $21[6,41]$. Isolated IEF are associated with an increased risk of Down syndrome, with likelihood ratios generally ranging from 1.5 to 5.0 [26]. In about $90 \%$ of cases they resolve by the third trimester of pregnancy [6]. In low risk populations for aneuploidy, the presence of an IEF is not an indication for invasive procedures and with negative FIS or NIPT it may be described as not clinically significant or as a normal variant. In cases of isolated IEF in euploid fetuses there is no evidence of an altered cardiac function and a detailed echocardiogram is not recommended as long as the second trimester scan is normal [42]. However, a few studies have suggested that diffuse echogenicity in the fetal heart, especially when the right ventricle is also involved, may signal a poor prognosis and deserves a further search for associated pathologies $[27,28]$. Postnatal cardiac functions after the presence of prenatally diagnosed IEF are not associated with myocardial dysfunction during childhood [41,43].

\section{Echogenic bowel}

Echogenic bowel is defined as fetal bowel of similar or greater echogenicity than the surrounding bone or fetal liver. Two-third of them was detected during the first and the second trimesters with the prevalence ranging from 0.2 to $1.8 \%$. Echogenic bowel resolves spontaneously in $19.7 \%$ of cases and the association with Down syndrome reported likelihood ratio of 5.5 to 6.7 [13]. Echogenic bowel has been described as normal variant, but may be associated with congenital viral infections (particularly CMV), aneuploidy, intra-amniotic bleeding, severe uteroplacental insufficiency, meconium peritonitis, cystic fibrosis, anemia, and fetal growth restriction (FGR) $[3,6,13]$. Therefore, a comprehensive examination and evaluation for CMV infection is suggested, in addition to correlation with aneuploidy testing results. Catania et al. [12] reported both pregnancy and neonatal outcomes by the time of echogenic bowel detected. Studies advocate serial fetal growth assessment when isolated echogenic bowel was detected at the first and the second trimester because it is associated with FGR and increase in intrauterine fetal demise (relative risk [RR] 1.6 for FGR and 8.6 for intrauterine fetal demise). If echogenic bowel was detected during the third trimester, the likelihood of postnatal surgical intervention for intestinal anomalies is significantly increased (0.9 to 7\%) [12,29]. However, Patel et al. [44] has provided some reassurance that there was no evidence of any serious long term bowel disease associated with isolated fetal echogenic bowel.

\section{Shortened humerus length and femur length}

Shortened humerus and femur are defined as bone length below the 5th percentile for gestational age [30]. Shortened humerus length $(\mathrm{HL})$ and femur length $(\mathrm{FL})$ was observed in 0.4 to $3.9 \%$ of normal fetus [26]. Fetal short long bones have been associated with aneuploidy, skeletal dysplasia, fetal structural anomalies, preeclampsia, stillbirth and FGR. Trisomy 21, 18, 13 
or an unbalanced autosomal structural abnormality are associated with relative short FL (risk 1:123;95\% Cl, 79-192) [31]. In the study of Kaijomaa et al. [30], isolated shorted HL and FL in second trimester demonstrated higher rates of preterm delivery and preeclampsia. The possible etiology is not yet fully understood, but it may be of placental origin. Other studies have also reported that isolated short FL was associated with a significantly higher RR for small-for gestational age infants (odds ratio $[\mathrm{OR}], 4.3-4.4 ; 95 \% \mathrm{Cl}, 3.8-4.8$ ) and early preterm delivery (OR, $4.2 ; 95 \% \mathrm{Cl}, 3.5-4.9)[31,32]$. Short HL and $\mathrm{FL}$ may be an early sign of placental dysfunction and warrant increased antenatal surveillance with repeated sonography for growth assessment and frequent blood pressure measurements [32].

\section{Fetal pyelectasis}

Fetal pyelectasis is defined as an anteroposterior measurement in a transverse scanning plane of $4 \mathrm{~mm}$ or larger in second trimester and/or $7 \mathrm{~mm}$ or larger in third trimester, whereas pelvic anteroposterior diameter $10 \mathrm{~mm}$ or larger is criteria for hydronephorosis $[4,45]$. The prevalence of pyelectasis varies from 0.1 to $2.4 \%$ in low risk populations [1]. While most commonly fetal pyelectasis is a transient physiologic state, it can be a marker for aneuploidy and be a precursor of potential urinary tract pathology [3]. The majority of cases of pyelectasis detected in the second trimester will resolve either before delivery or within the first year of postnatal life $[13,15]$. Isolated mild pyelectasis in low risk population is not the evidence of increased risk of aneuploidy and therefore it cannot be considered as an indication for the determination of the karyotype $[4,15]$. A prenatal progression of dilatation of pyelectasis was directly related to a worse outcome [15]. Therefore, a follow-up ultrasound at 32 weeks of gestation to rule out persistent pyelectasis should be performed. At this time, approximately half of cases will be normal, $30 \%$ will continue to have mild pyelectasis, and 15\% will have more significant hydronephrosis. If the renal pelvis measures $>7 \mathrm{~mm}$ at 30 week examination, postnatal follow-up is suggested $[14,15]$.

\section{Single umbilical artery}

SUA is characterized by absence of one of umbilical arteries and it occurs in 0.5 to $5 \%$ of pregnancies. SUA appears to be an isolated finding in $60-80 \%$ of cases $[4,33,34]$. Controversy exists regarding the association between aneuploidy, small for gestational age (SGA), preterm birth and isolated SUA. Some studies have shown a higher risk of SGA, preterm birth, pregnancy- induced hypertension, admission to the neonatal intensive care unit, and perinatal mortality $[33,35]$. Isolated SUA was associated with a higher rate of cesarean section due to nonreassuring fetal heart rate, $\mathrm{SGA}$, and a higher rate of placenta or umbilical cord abnormalities [35,36]. Controversially, the metaanalysis of Voskamp et al. [34] showed no statistically significant difference in aneuploidy rate, birth weight and incidence of FGR between isolated SUA fetuses and three vessel cord fetuses, and concluded targeted growth assessment should not be a routine practice.

\section{Conclusion}

It is important to understand the characteristics of each soft marker to prevent unnecessary karyotyping and to perform necessary karyotyping. With rapid implementation of NIPT as a new method of prenatal testing for Down syndrome or other common aneuploidies in the first trimester, it became easier to deal with soft markers. Diagnostic testing should not be recommended to patients with an isolated soft marker in the setting of a negative NIPT result [9]. Also, looking for soft markers of trisomy 21 , should not be performed in women with a normal NIPT result due to its high false-positive rate and poor positive predictive value [11]. However, soft marker screening still remains a tool in screening for non-aneuploidy-related conditions such as, structural anomalies and adverse pregnancy outcomes that requires follow-up during pregnancy. This article proposed a simple clinical summary for management of specific soft markers. Patients with fetus with specific soft markers mentioned above may be reassured that the pregnancy outcomes and the long-term outcomes are generally favorable. Furthermore, more studies are needed to establish standard guidelines and to facilitate the application of soft markers to the clinical practice in Koreans.

\section{References}

1. Ahman A, Axelsson O, Maras G, Rubertsson C, Sarkadi A, Lindgren P. Ultrasonographic fetal soft markers in a low-risk population: prevalence, association with trisomies and invasive tests. Acta Obstet Gynecol Scand 2014;93:367-73.

2. Hurt L, Wright M, Brook F, Thomas S, Dunstan F, Fone $D$, et al. The Welsh study of mothers and babies: protocol for a population-based cohort study to investigate the clinical significance of defined ultrasound findings of uncertain significance. BMC Pregnancy Childbirth 2014;14:164 
3. Hurt L, Wright M, Dunstan F, Thomas S, Brook F, Morris S, et al. Prevalence of defined ultrasound findings of unknown significance at the second trimester fetal anomaly scan and their association with adverse pregnancy outcomes: the Welsh study of mothers and babies population-based cohort. Prenat Diagn 2016;36:40-8.

4. Stefanovic $V$. Soft markers for aneuploidy following reassuring first trimester screening: what should be done? Curr Opin Obstet Gynecol 2015;27:151-8.

5. Liau J, Romine L, Korty LA, Chao C, White K, Harmon S, et al. Simplifying the ultrasound findings of the major fetal chromosomal aneuploidies. Curr Probl Diagn Radiol 2014;43:300-16.

6. Cicero S, Sacchini C, Rembouskos G, Nicolaides KH. Sonographic markers of fetal aneuploidy--a review. Placenta 2003;24 Suppl B:S88-98

7. Russo ML, Blakemore KJ. A historical and practical review of first trimester aneuploidy screening. Semin Fetal Neonatal Med 2014;19:183-7.

8. Schwartz S, Kohan M, Pasion R, Papenhausen PR, Platt LD. Clinical experience of laboratory follow-up with noninvasive prenatal testing using cell-free DNA and positive microdeletion results in 349 cases. Prenat Diagn 2018;38:210-8.

9. Norton ME, Biggio JR, Kuller JA, Blackwell SC; Society for MaternalFetal Medicine (SMFM). The role of ultrasound in women who undergo cell-free DNA screening. Am J Obstet Gynecol 2017;216:B2-7.

10. Bromley B, Shipp TD, Lyons J, Groszmann Y, Navathe RS, Benacerraf BR. What is the importance of second-trimester "soft markers" for trisomy 21 after an 11- to 14-week aneuploidy screening scan? J UItrasound Med 2014;33:1747-52.

11. Salomon $\sqcup$, Alfirevic Z, Audibert F, Kagan KO, Paladini D, Yeo G, et al. ISUOG consensus statement on the impact of non-invasive prenatal testing (NIPT) on prenatal ultrasound practice. Ultrasound Obstet Gynecol 2014;44:122-3.

12. Catania VD, Taddei A, Pellegrino M, De Marco EA, Merli L, Manzoni $C_{1}$ et al. Hyperechogenic bowel: etiologies, management, and outcome according to gestational age at diagnosis in 279 consecutive cases in a single center. Eur J Pediatr Surg 2017;27:109-15.

13. Norton ME. Follow-up of sonographically detected soft markers for fetal aneuploidy. Semin Perinatol 2013;37:365-9.

14. Mallik $M$, Watson AR. Antenatally detected urinary tract abnormalities: more detection but less action. Pediatr Nephrol 2008;23:897904.

15. Signorelli M, Cerri V, Taddei F, Groli C, Bianchi UA. Prenatal diagnosis and management of mild fetal pyelectasis: implications for neonatal outcome and follow-up. Eur J Obstet Gynecol Reprod Biol 2005:118:154-9.

16. Scala C, Familiari A, Pinas A, Papageorghiou AT, Bhide A, Thilagana- than $\mathrm{B}$, et al. Perinatal and long-term outcomes in fetuses diagnosed with isolated unilateral ventriculomegaly: systematic review and meta-analysis. Ultrasound Obstet Gynecol 2017;49:450-9.

17. Bar-Yosef O, Barzilay E, Dorembus S, Achiron R, Katorza E. Neurodevelopmental outcome of isolated ventriculomegaly: a prospective cohort study. Prenat Diagn 2017;37:764-8.

18. Weichert J, Hartge D, Krapp M, Germer U, Gembruch U, Axt-Fliedner R. Prevalence, characteristics and perinatal outcome of fetal ventriculomegaly in 29,000 pregnancies followed at a single institution. Fetal Diagn Ther 2010;27:142-8.

19. Pagani G, Thilaganathan B, Prefumo F. Neurodevelopmental outcome in isolated mild fetal ventriculomegaly: systematic review and metaanalysis. Ultrasound Obstet Gynecol 2014;44:254-60.

20. Beke A, Barakonyi E, Belics Z, Joó JG, Csaba A, Papp C, et al. Risk of chromosome abnormalities in the presence of bilateral or unilateral choroid plexus cysts. Fetal Diagn Ther 2008;23:185-91.

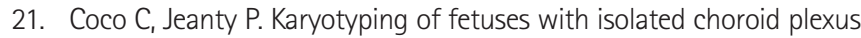
cysts is not justified in an unselected population. J Ultrasound Med 2004:23:899-906

22. DiPietro JA, Cristofalo EA, Voegtline KM, Crino J. Isolated prenatal choroid plexus cysts do not affect child development. Prenat Diagn $2011 ; 31: 745-9$.

23. Cicero S, Curcio P, Papageorghiou A, Sonek J, Nicolaides K. Absence of nasal bone in fetuses with trisomy 21 at 11-14 weeks of gestation: an observational study. Lancet 2001;358:1665-7.

24. Dukhovny S, Wilkins-Haug L, Shipp TD, Benson CB, Kaimal AJ, Reiss R. Absent fetal nasal bone: what does it mean for the euploid fetus? J Ultrasound Med 2013;32:2131-4.

25. Jelliffe-Pawlowski LL, Walton-Haynes L, Currier RJ. Identification of second trimester screen positive pregnancies at increased risk for congenital heart defects. Prenat Diagn 2009;29:570-7.

26. Nyberg DA, Souter VL, El-Bastawissi A, Young S, Luthhardt F, Luthy DA. Isolated sonographic markers for detection of fetal Down syndrome in the second trimester of pregnancy. J Ultrasound Med 2001;20:1053-63.

27. Rodriguez $R$, Herrero $B, B a r t h a ~ J L$. The continuing enigma of the fetal echogenic intracardiac focus in prenatal ultrasound. Curr Opin Obstet Gynecol 2013;25:145-51.

28. Bronshtein $\mathrm{M}$, Jakobi $\mathrm{P}$, Ofir $\mathrm{C}$. Multiple fetal intracardiac echogenic foci: not always a benign sonographic finding. Prenat Diagn 1996;16:131-5.

29. Goetzinger KR, Cahill AG, Macones GA, Odibo AO. Echogenic bowel on second-trimester ultrasonography: evaluating the risk of adverse pregnancy outcome. Obstet Gynecol 2011;117:1341-8.

30. Kaijomaa M, Ulander VM, Ryynanen M, Stefanovic V. Risk of adverse outcomes in euploid pregnancies with isolated short fetal femur 
and humerus on second-trimester sonography. J Ultrasound Med 2016;35:2675-80.

31. Mathiesen JM, Aksglaede L, Skibsted L, Petersen OB, Tabor A; Danish Fetal Medicine Study Group. Outcome of fetuses with short femur length detected at second-trimester anomaly scan: a national survey. Ultrasound Obstet Gynecol 2014;44:160-5.

32. Aviram A, Bardin R, Wiznitzer A, Yogev $Y$, Hadar E. Midtrimester isolated short femur length as a predictor of adverse pregnancy outcome. Fetal Diagn Ther 2015;38:205-11.

33. Kim HJ, Kim JH, Chay DB, Park JH, Kim MA. Association of isolated single umbilical artery with perinatal outcomes: systemic review and meta-analysis. Obstet Gynecol Sci 2017;60:266-73.

34. Voskamp BJ, Fleurke-Rozema H, Oude-Rengerink K, Snijders RJ, Bilardo CM, Mol BW, et al. Relationship of isolated single umbilical artery to fetal growth, aneuploidy and perinatal mortality: systematic review and meta-analysis. Ultrasound Obstet Gynecol 2013;42:6228.

35. Battarbee AN, Palatnik A, Ernst LM, Grobman WA. Association of isolated single umbilical artery with small for gestational age and preterm birth. Obstet Gynecol 2015;126:760-4.

36. Ashwal E, Melamed N, Hiersch L, Edel S, Bardin R, Wiznitzer A, et al. The impact of isolated single umbilical artery on labor and delivery outcome. Prenat Diagn 2014;34:581-5.

37. Malinger G, Lev D, Lerman-Sagie T. Imaging of fetal cytomegalovirus infection. Fetal Diagn Ther 2011;29:117-26.

38. Pasquini L, Seravalli V, Sisti G, Battaglini C, Nepi F, Pelagalli R, et al. Prevalence of a positive TORCH and parvovirus B19 screening in pregnancies complicated by polyhydramnios. Prenat Diagn 2016;36:290-3.

39. Jung $E$, Won HS, Lee PR, Kim A. Ultrasonographic measurement of fetal nasal bone length in the second trimester in Korean population. Prenat Diagn 2007;27:154-7.

40. Abele H, Wagner P, Sonek J, Hoopmann M, Brucker S, Artunc-Ulkumen $B$, et al. First trimester ultrasound screening for Down syndrome based on maternal age, fetal nuchal translucency and different combinations of the additional markers nasal bone, tricuspid and ductus venosus flow. Prenat Diagn 2015;35:1182-6.

41. Wax JR, Donnelly J, Carpenter M, Chard R, Pinette MG, Blackstone J, et al. Childhood cardiac function after prenatal diagnosis of intracardiac echogenic foci. J Ultrasound Med 2003;22:783-7.

42. Perles Z, Nir A, Gavri S, Golender J, Rein AJ. Intracardiac echogenic foci have no hemodynamic significance in the fetus. Pediatr Cardiol 2010;31:7-10.

43. Gupta G, Aggarwal S, Phadke SR. Intracardiac echogenic focus and fetal outcome. J Clin Ultrasound 2010;38:466-9.

44. Patel Y, Boyd PA, Chamberlain P, Lakhoo K. Follow-up of children with isolated fetal echogenic bowel with particular reference to bowelrelated symptoms. Prenat Diagn 2004;24:35-7.

45. Odibo AO, Marchiano D, Quinones JN, Riesch D, Egan JF, Macones GA. Mild pyelectasis: evaluating the relationship between gestational age and renal pelvic anterior-posterior diameter. Prenat Diagn 2003;23:824-7. 